\title{
The evolution of light and vertical mixing across a phytoplankton ice edge bloom
}

Supplementary Material

Achim Randelhoff, Laurent Oziel, Philippe Massicotte, Guislain Bécu, Martí Galí, Léo Lacour, Dany Dumont, Anda Vladoiu, Claudie Marec, Flavienne Bruyant, Marie-Noëlle Houssais, Jean-Éric Tremblay, Gabrièle Deslongchamps, Marcel Babin achim.randelhoff@takuvik.ulaval.ca 


\section{List of Figures}

1.1 MODIS true color image from 26 April 2016. Markers show hydrographic stations. . . . . 4

1.2 MODIS true color image from 1 June 2016. Markers show hydrographic stations. . . . . . 5

1.3 MODIS true color image from 11 July 2016. Markers show hydrographic stations. . . . . . 5

1.4 Monthly averages of chlorophyll-a and sea surface temperature (SST) in Baffin Bay; the black line shows the ice edge. . . . . . . . . . . . . . . . . . . . .

2.1 Density Mixed Layer depth ( $\mathrm{m}$ ) (at the time of sampling). For completeness' sake and to make our results comparable with other studies, notably the study by Peralta-Ferriz and Woodgate (2015) mentioned above and Oziel et al.'s companion paper (Oziel et al., 2018, this issue), we here computed a mixed layer depth as the shallowest depth where potential density exceeds the surface density by $0.1 \mathrm{~kg} \mathrm{~m}^{-3}$. Note, however, that this yields a density mixed layer and is therefore extremely shallow under the conditions presented here. . . . . . . . . . . . . . . . . . . . .

2.2 Sea ice concentration $(\%)$ (at the time of sampling) . . . . . . . . . . . . . . .

2.3 Temperature $\max \left({ }^{\circ} \mathrm{C}\right)($ at the time of sampling) $\ldots \ldots \ldots \ldots \ldots$

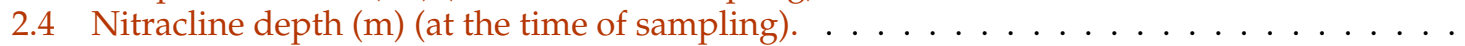

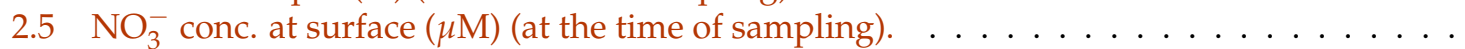

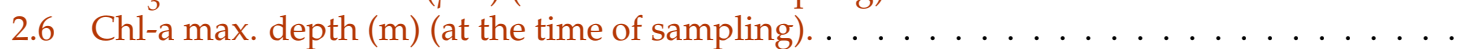

$2.7 \Delta \sigma_{\theta}\left(\mathrm{kg} \mathrm{m}^{-3}\right)($ at the time of sampling $) \ldots \ldots \ldots \ldots \ldots \ldots$

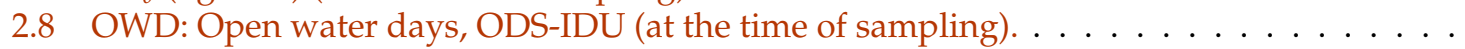

2.9 ODS: Days of open water since ice retreat (at the time of sampling). . . . . . . . . . . .

2.10 IDU: Days until ice retreat (at the time of sampling) . . . . . . . . . . . . . . . . . . . . . . . . .

2.11 TChl-a, vertically integrated $\left(\mathrm{mg} \mathrm{m}^{-2}\right)$ (at the time of sampling) . . . . . . . . . . . . 12

2.12 Isolume ( $\mathrm{z}$ at $0.415 \mathrm{~mol}$ photons $\mathrm{m}^{-2} \mathrm{~d}^{-1}$ ) (at the time of sampling). . . . . . . . . . . . . 12

$2.13 \mathrm{NO}_{3}^{-}$conc. at overturning depth $(\mu \mathrm{M})$ (at the time of sampling) . . . . . . . . . . . . 13

2.14 T-S plot. The color scale represents Depth. . . . . . . . . . . . . . . . . . . . . . . . 13

2.15 T-S plot. The color scale represents the ANP tracer. . . . . . . . . . . . . . . . . . . . . 14

2.16 The depth of maximum $\mathrm{N}^{2}$ compared to (left) the equivalent mixed layer depth $\mathrm{h}_{\mathrm{BD}}$, and (right) a classical mixed layer depth defined by a $0.1 \mathrm{~kg} \mathrm{~m}^{-3}$ threshold. Solid black line: $1: 1$ relation. . . . . . . . . . . . . . . . . . . . . . . . 14

3.1 Left: Days until the ice retreats vs. days since the ice has retreated. Right: Comparison of two different criteria to define the OWD variable. . . . . . . . . . . . . .

4.1 The 0.415 mol photons $\mathrm{m}^{-2} \mathrm{~d}^{-1}$ isolume plotted against the $1 \%$ PAR level, a common definition of the euphotic zone depth. The slope as determined by a linear regression is not significantly different from one.

.2 The combined ice+snow transmittance where available; empty circles mean that measurements were not done from the ice. Estimated from C-OPS measurements as the ratio between downwelling PAR irradiance directly under sea ice and the simultaneously measured incoming above-surface PAR. . . . . . . . . . . . . . . . . .

4.3 Isolumes compared between the 0.1 and the 0.415 mol photons $\mathrm{m}^{-2} \mathrm{~d}^{-1}$ light levels. . .

4.4 PAR irradiance averaged over the equivalent mixed layer depth $\mathrm{h}_{B D} \ldots \ldots$. . . . . . . .

4.5 Scatterplot for the Amundsen cruise and a period of 3h prior to sampling (left), model/measurement ratio sorted by sea ice concentration (center), and boxplot of the model/measurement ratio sorted by five sea ice concentration categories (right) . . . . . . . .

5.1 Salinity, temperature, and ANP tracer averaged in bins $0<0.1<0.9<1$ of the clustering

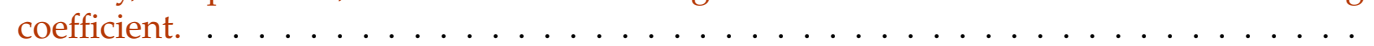

6.1 Left: Freezing point deviation plotted against salinity, split by hydrographic domain. For individual profiles, see Figs. S6.2 and S6.3. Right: Nitrate concentrations against salinity split by hydrographic domain. Although somewhat skewed because surface nitrate consumption had progressed more in the Atlantic than the Arctic domain, it shows how winter overturning to more saline layers gives access to more pre-bloom nitrate. . .

6.2 Temperature-salinity diagram showing detected temperature minima (black) in the "Arctic" domain. . . . . . . . . . . . . . . . . . . . . . . . .

6.3 Temperature-salinity diagram showing detected minima (black) in the "Atlantic" domain.

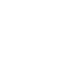
14 (n) 5 
6.4 Winter surface concentration of nitrate taken as nitrate concentration at the estimated winter overturning salinity, plotted against the number of open water days. Note that in the easternmost stations (high OWD values), phytoplankton growth may have decreased nitrate concentrations at the winter overturning depth, and there winter surface concentrations may be more in the $10 \mu \mathrm{M}$ range. . . . . . . . . . . . . . . . . 22

6.5 The chl-a maximum stayed below the nitracline at most stations. . . . . . . . . . . 23

7.1 Nitrate vs phosphate, also showing regression relations by Jones et al. (1998). . . . . . . . 24

8.1 Vertical profiles of total chlorophyll-a as measured by HPLC, showing that very little biomass is lost by uniformly integrating from 0 to $80 \mathrm{~m}$ depth. . . . . . . . . . . . . . . 25

8.2 Underestimation of total chlorophyll by integration of HPLC-determined profiles to $80 \mathrm{~m}$, vs. closing them using CTD/rosette-based fluorescence sensor. Left panel: Two exemplary profiles of HPLC-determined total chlorophyll, and the corresponding CTD fluorescence sonde output (bias removed and smoothed using a 5-point running median filter followed by a 7-point running mean filter). The horizontal dashed black line marks the depth of the deepest TChla measurement while the dashed grey line marks the depth where only $1 \%$ of the maximum value of the Chla profile remains. Right panel: The underestimation of vertically integrated total chl-a by only integrating the HPLC profile, compared to integrating the complete fluorescence profile, as a function of open water days (OWD). The differences are small, which is why we used the simple vertical integration of HPLC total chl-a in this study. The underestimation is then given by the difference between the rosette chl-a fluorescence integrated down to the maximum HPLC sampling depth, and the rosette chl-a fluorescence integrated down to the $1 \%$ fluorescence level. . . . . . . . . 26 


\section{Introduction}

This document provides supplementary material to our study on Baffin Bay hydrography and the environmental constraints during a phytoplankton bloom at the retreating ice edge. It provides more detail on some of the methods, but mostly shows more variables that may help the interested reader in getting a better overview over the immense dataset the Green Edge campaign has produced. All data are accessible at the Green Edge database (http://www.obs-vlfr.fr/proof/php/GREENEDGE/greenedge . $\mathrm{php})$.

\subsection{Acknowledgments}

This document was created as a Jupyter Lab notebook and exported to pdf partly using Chris Sewell's ipypublish template.

\subsection{More overview maps}

The following true color images are meant to provide more context for the campaign, especially with regards to floe sizes and general impressions of the ice cover that are hard to capture in sea ice concentration charts. Surface chlorophyll-a and sea temperature show the phytoplankton growth and warming trailing behind the retreating ice edge.

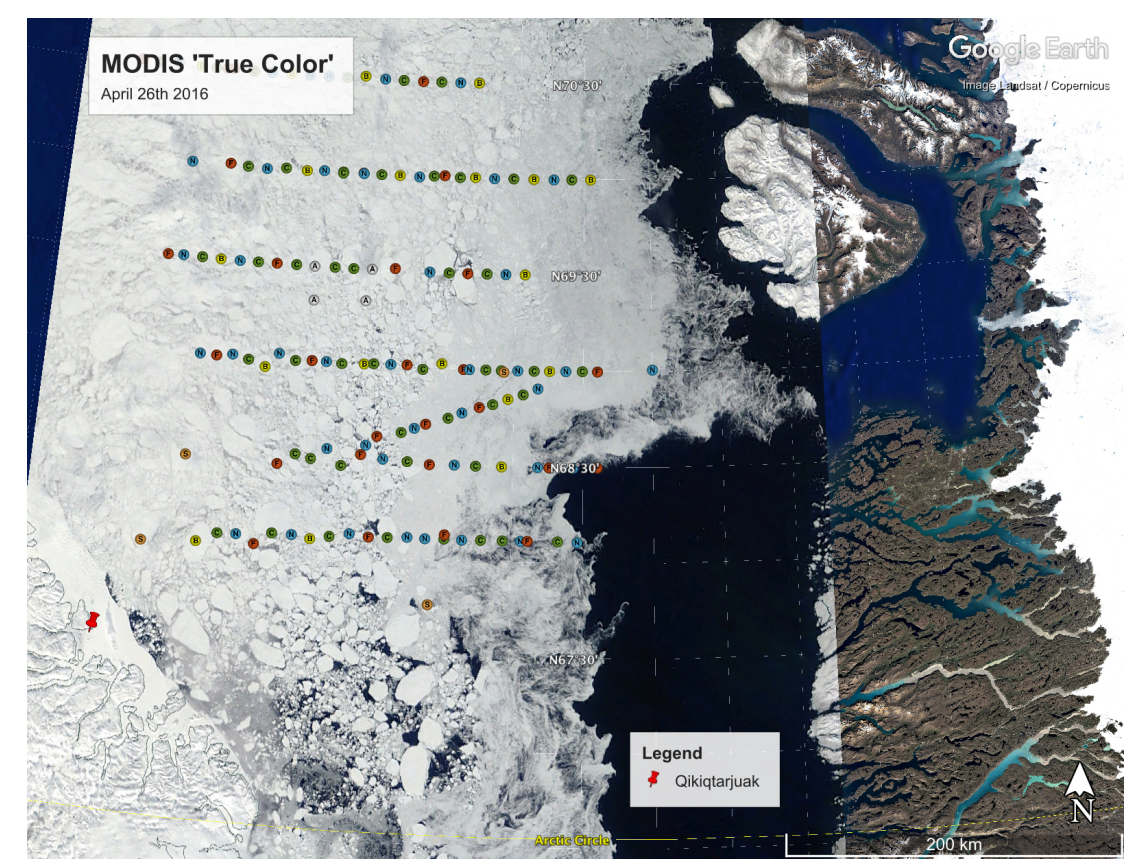

Figure 1.1: MODIS true color image from 26 April 2016. Markers show hydrographic stations. 


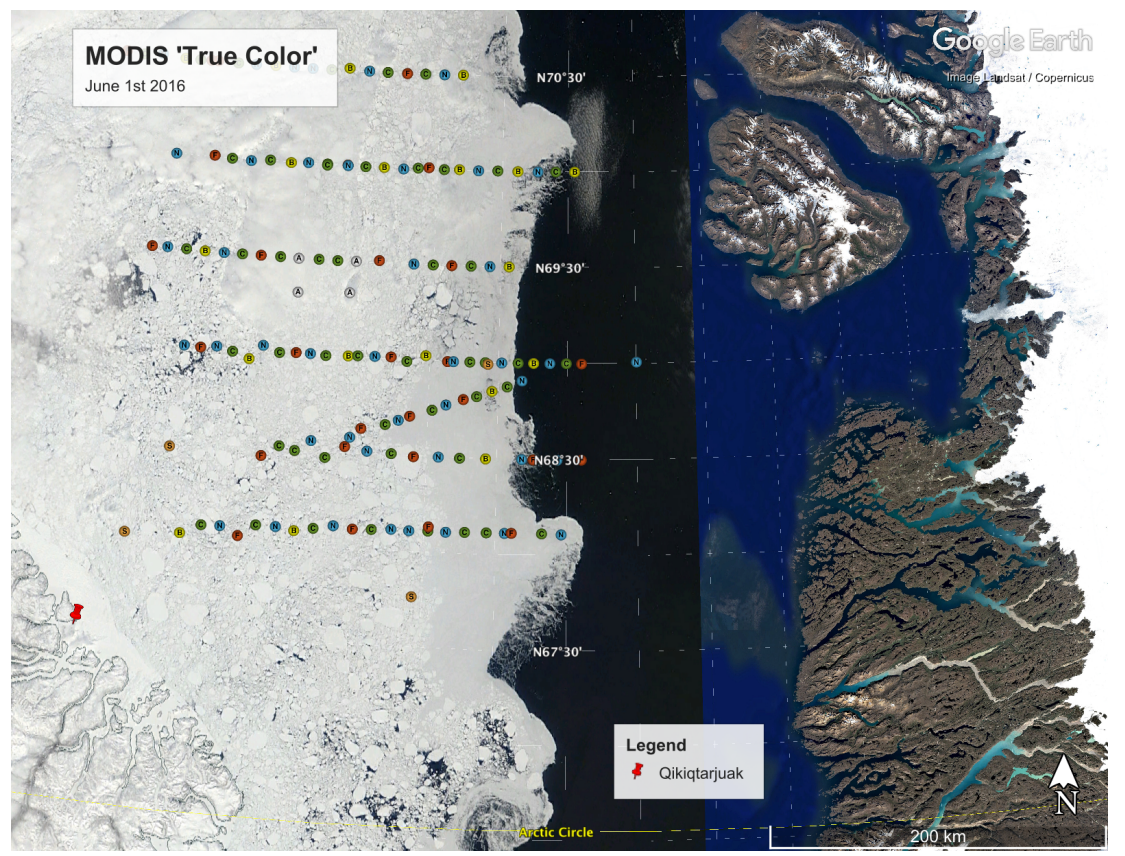

Figure 1.2: MODIS true color image from 1 June 2016. Markers show hydrographic stations.

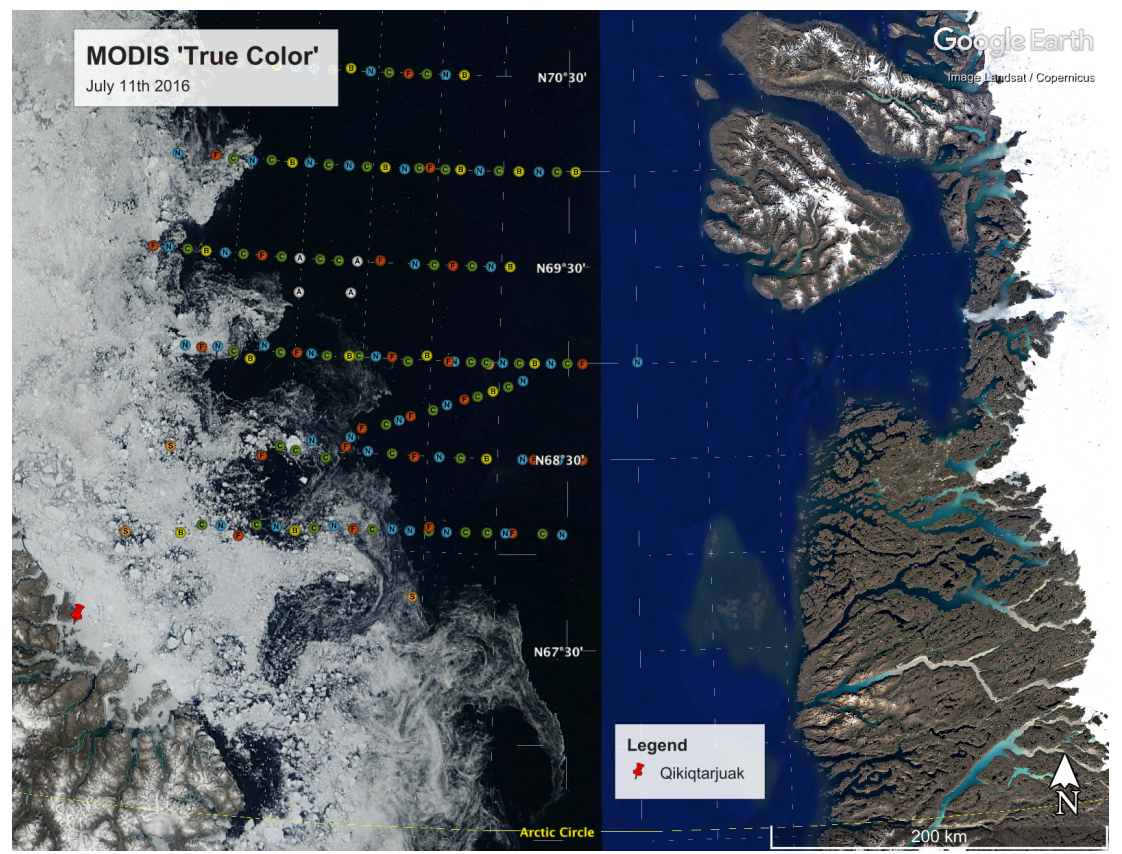

Figure 1.3: MODIS true color image from 11 July 2016. Markers show hydrographic stations. 

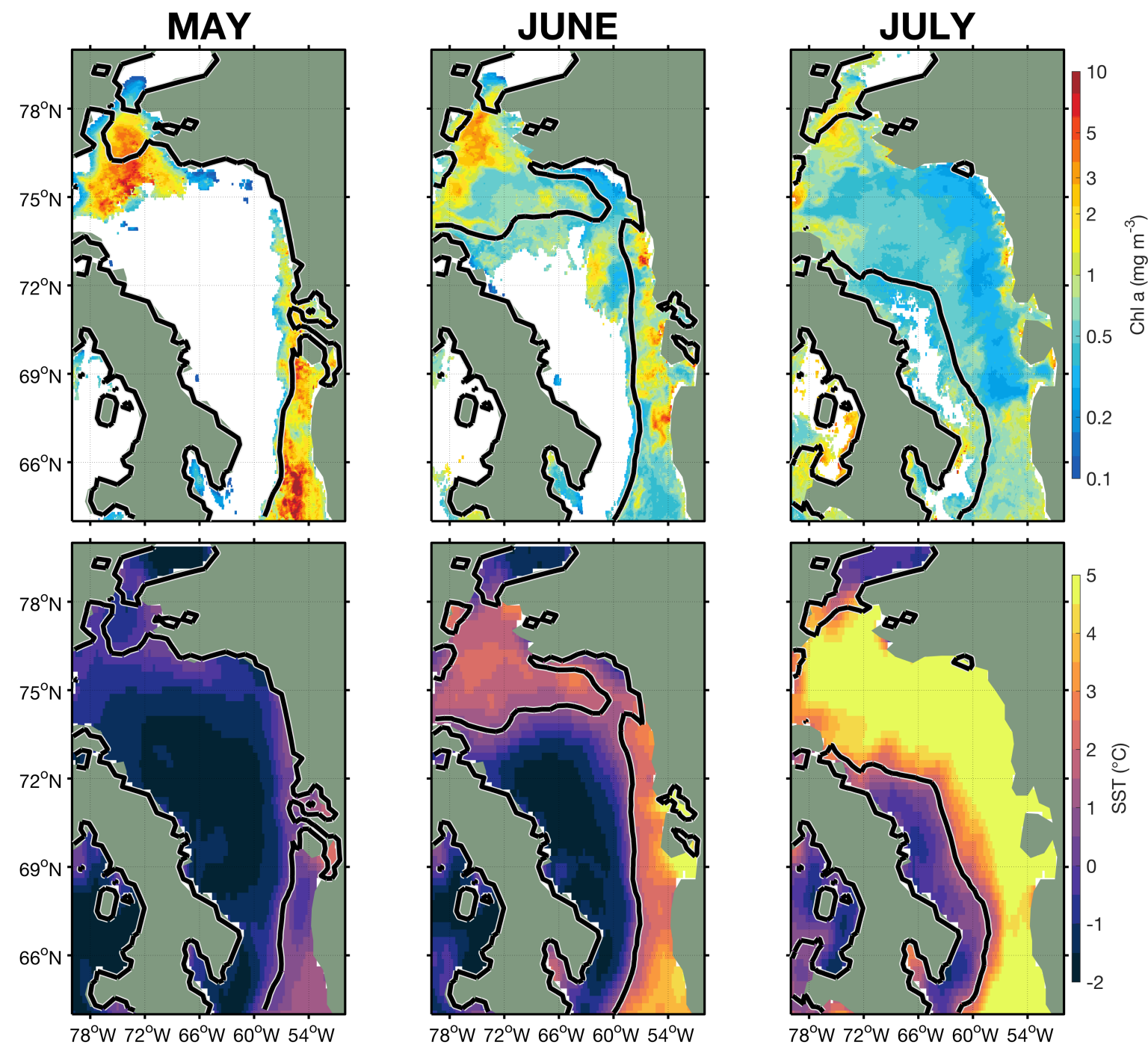

Figure 1.4: Monthly averages of chlorophyll-a and sea surface temperature (SST) in Baffin Bay; the black line shows the ice edge. 


\section{Hydrography - Some additional figures}

Some additional maps of various hydrographic properties, akin to Fig. 6 of the main paper.

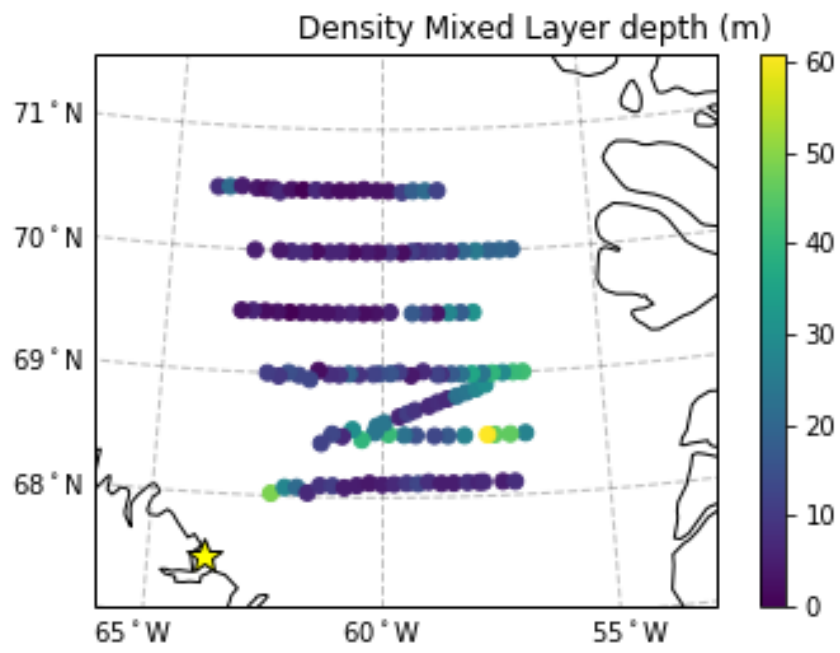

Figure 2.1: Density Mixed Layer depth (m) (at the time of sampling). For completeness' sake and to make our results comparable with other studies, notably the study by Peralta-Ferriz and Woodgate (2015) mentioned above and Oziel et al.'s companion paper (Oziel et al., 2018, this issue), we here computed a mixed layer depth as the shallowest depth where potential density exceeds the surface density by $0.1 \mathrm{~kg} \mathrm{~m}^{-3}$. Note, however, that this yields a density mixed layer and is therefore extremely shallow under the conditions presented here.

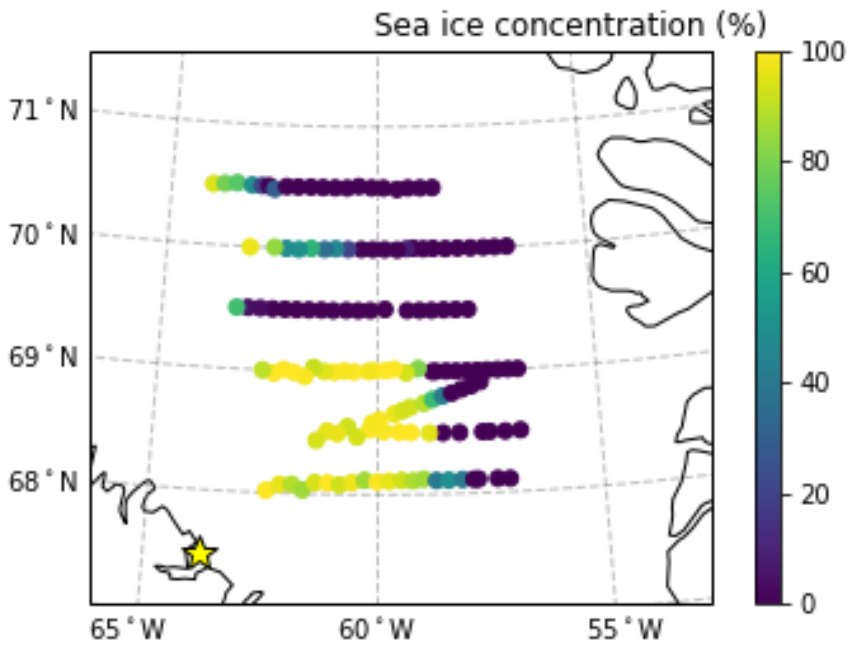

Figure 2.2: Sea ice concentration (\%) (at the time of sampling). 


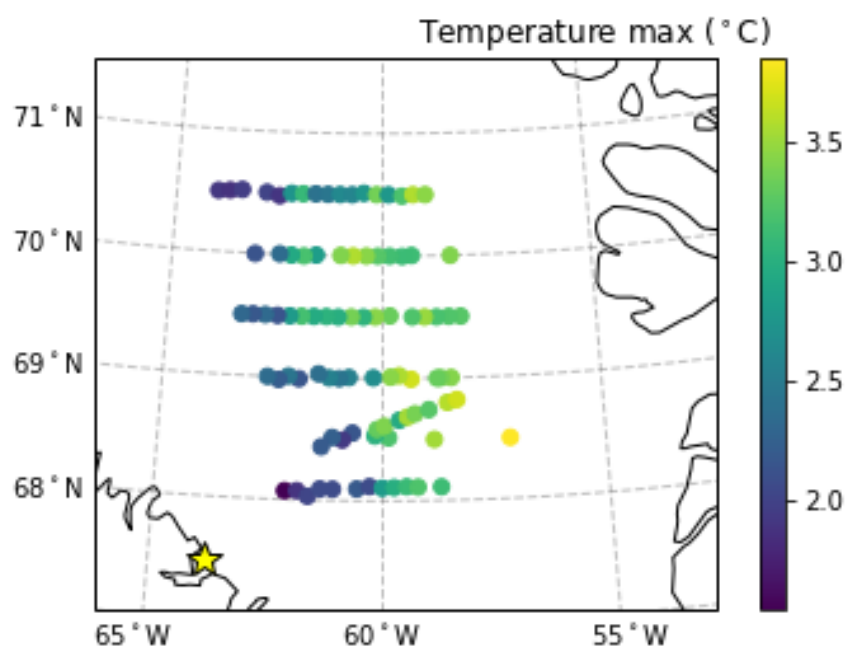

Figure 2.3: Temperature $\max \left({ }^{\circ} \mathrm{C}\right)$ (at the time of sampling).

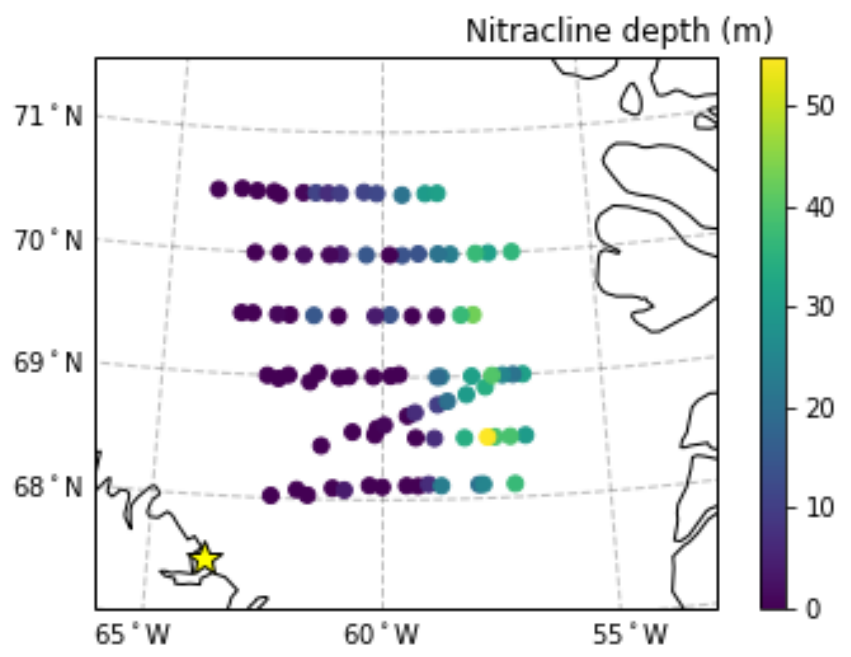

Figure 2.4: Nitracline depth (m) (at the time of sampling). 


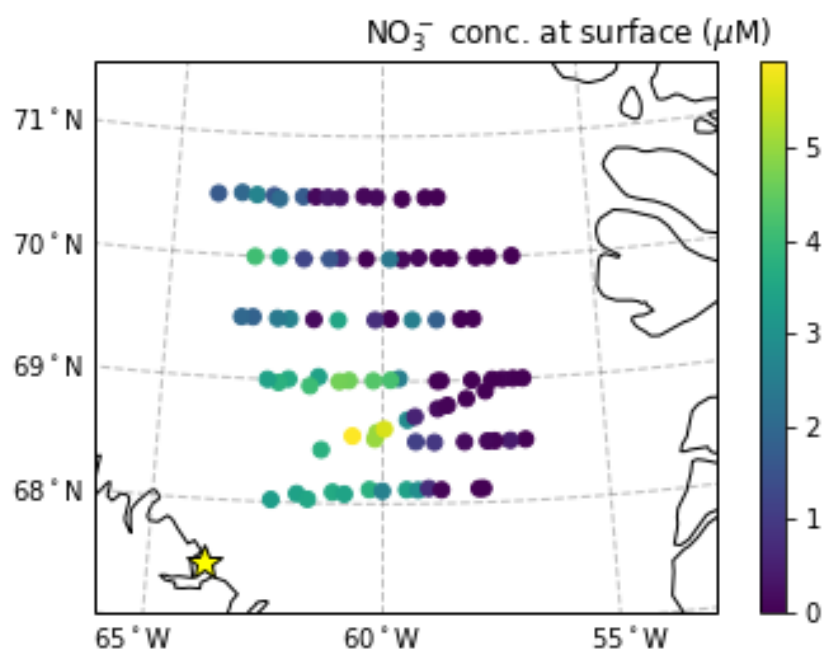

Figure 2.5: $\mathrm{NO}_{3}^{-}$conc. at surface $(\mu \mathrm{M})$ (at the time of sampling).

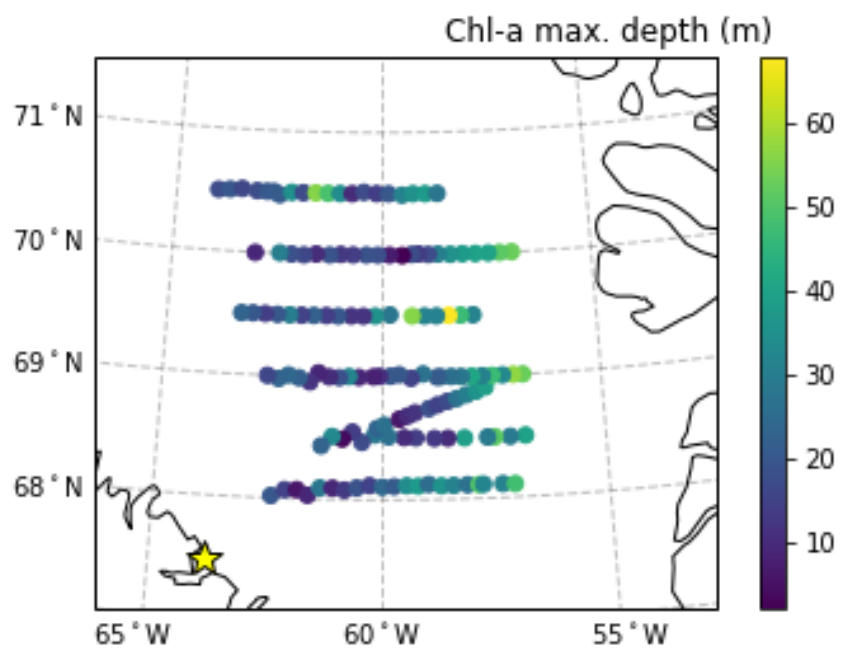

Figure 2.6: Chl-a max. depth (m) (at the time of sampling). 


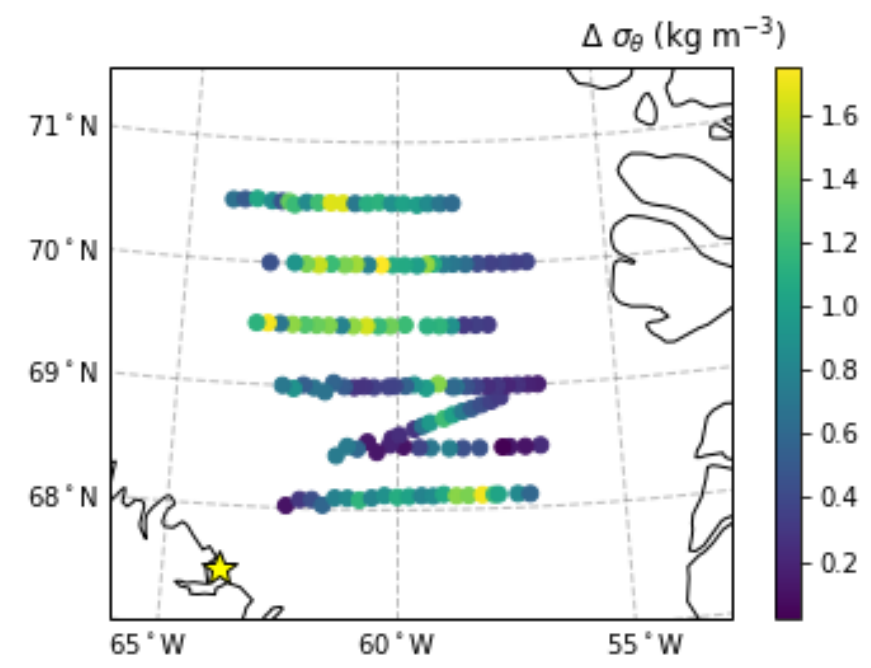

Figure 2.7: $\Delta \sigma_{\theta}\left(\mathrm{kg} \mathrm{m}^{-3}\right)$ (at the time of sampling).

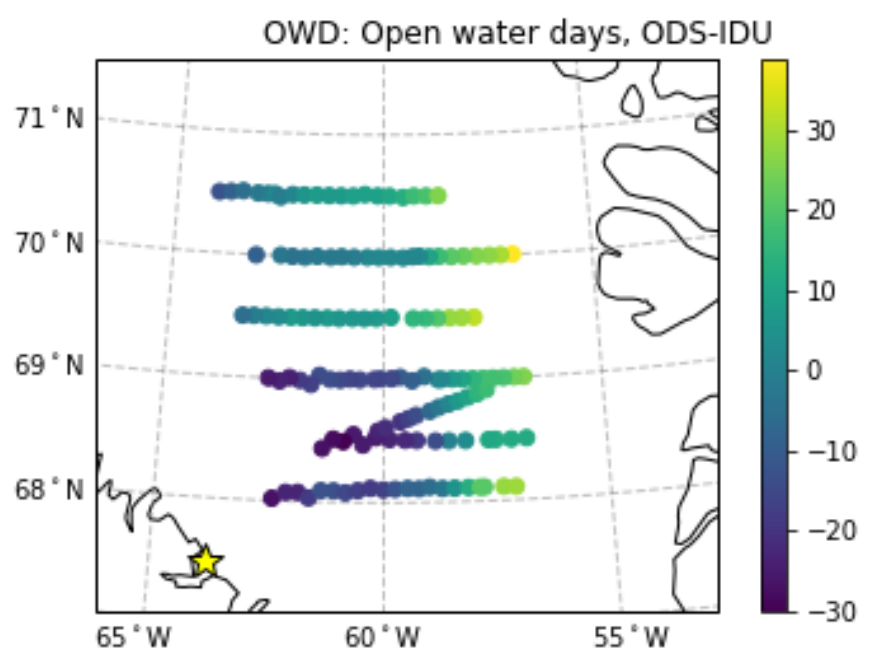

Figure 2.8: OWD: Open water days, ODS-IDU (at the time of sampling). 


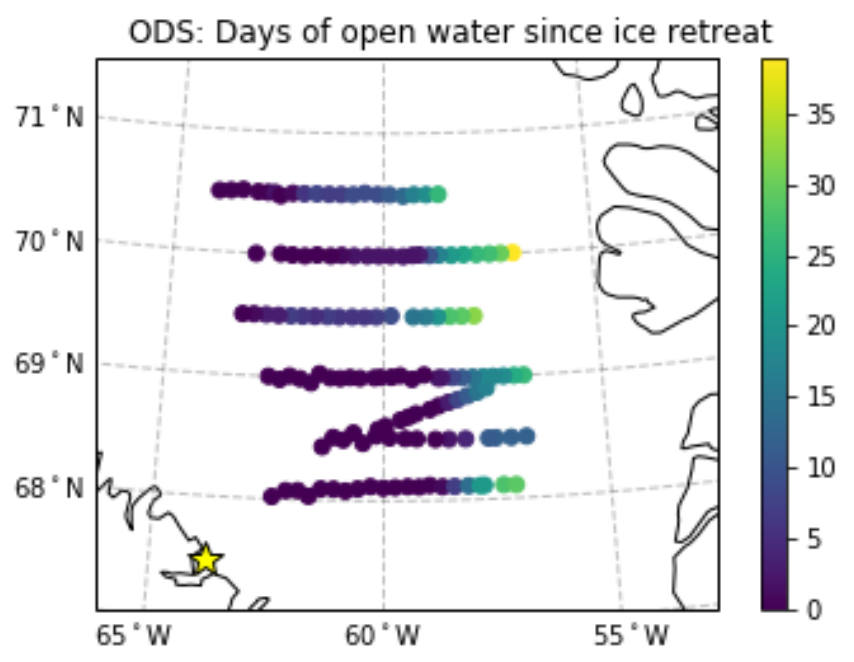

Figure 2.9: ODS: Days of open water since ice retreat (at the time of sampling).

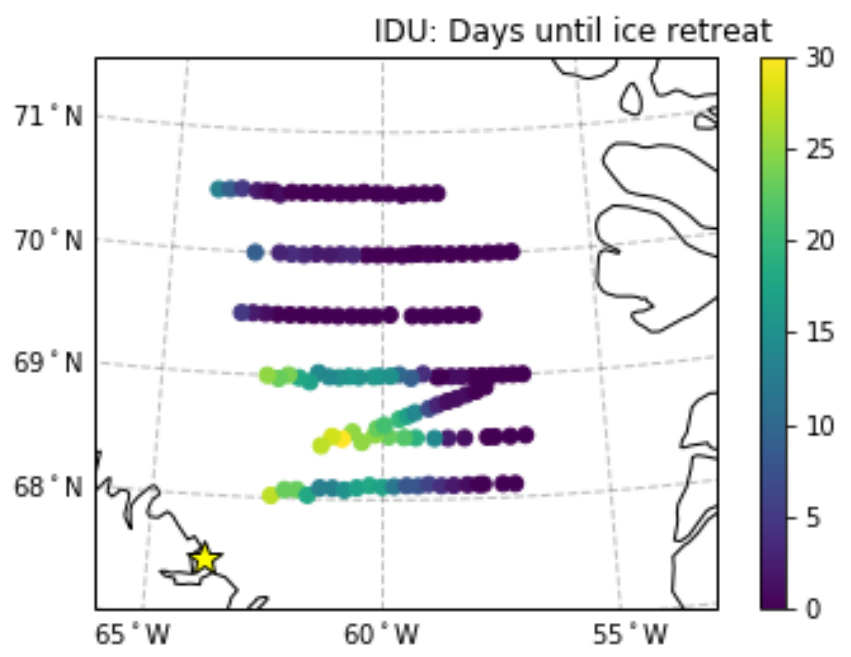

Figure 2.10: IDU: Days until ice retreat (at the time of sampling). 


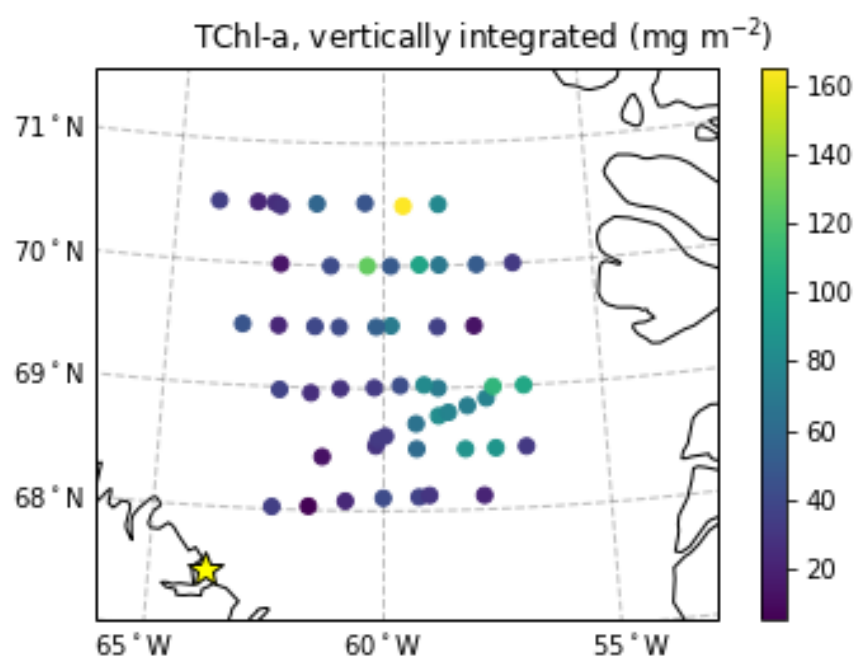

Figure 2.11: $\mathrm{TChl}-\mathrm{a}$, vertically integrated $\left(\mathrm{mg} \mathrm{m}^{-2}\right)$ (at the time of sampling).

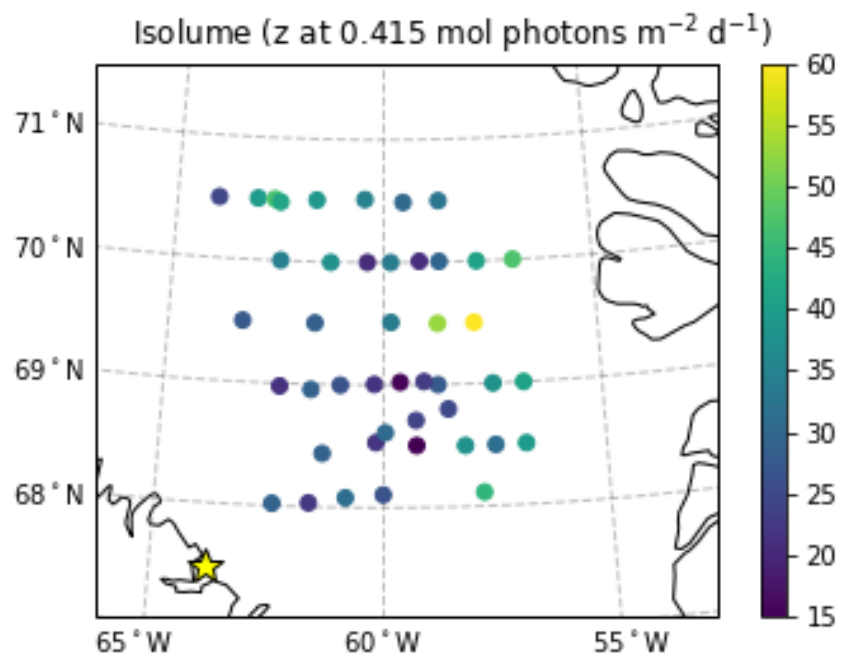

Figure 2.12: Isolume ( $\mathrm{z}$ at $0.415 \mathrm{~mol}$ photons $\mathrm{m}^{-2} \mathrm{~d}^{-1}$ ) (at the time of sampling). 


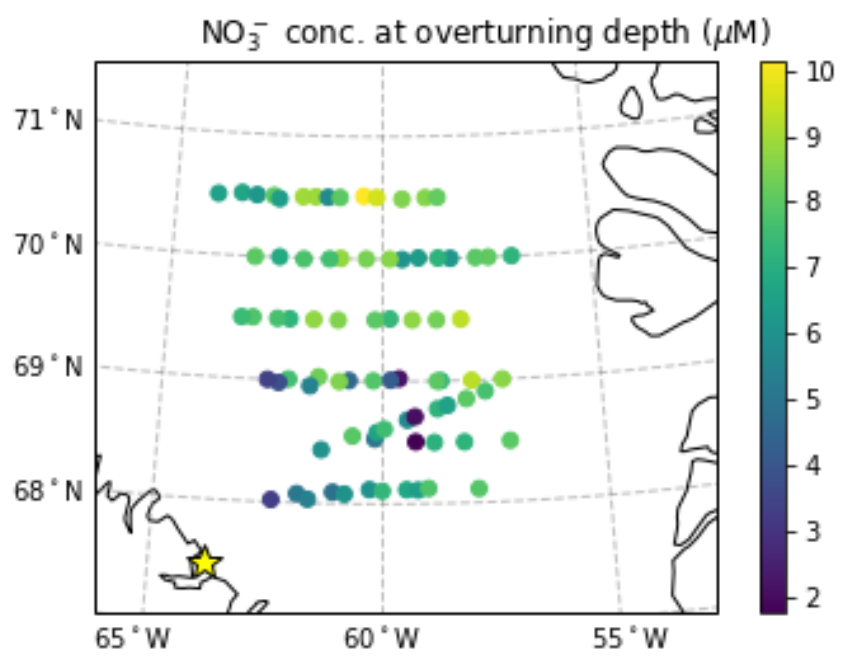

Figure 2.13: $\mathrm{NO}_{3}^{-}$conc. at overturning depth $(\mu \mathrm{M})$ (at the time of sampling).

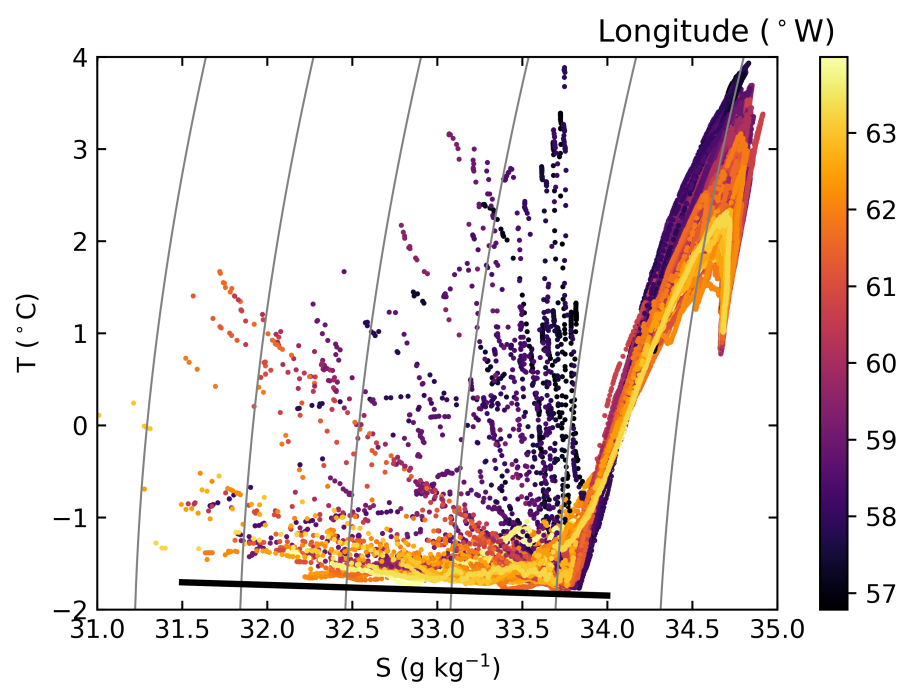

Figure 2.14: T-S plot. The color scale represents Depth. 


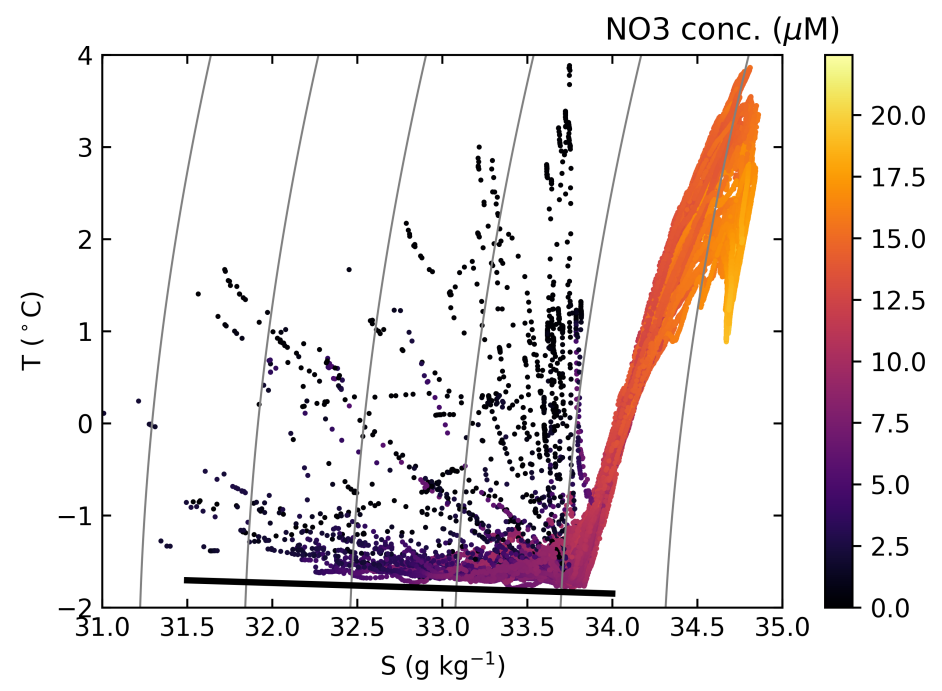

Figure 2.15: T-S plot. The color scale represents the ANP tracer.
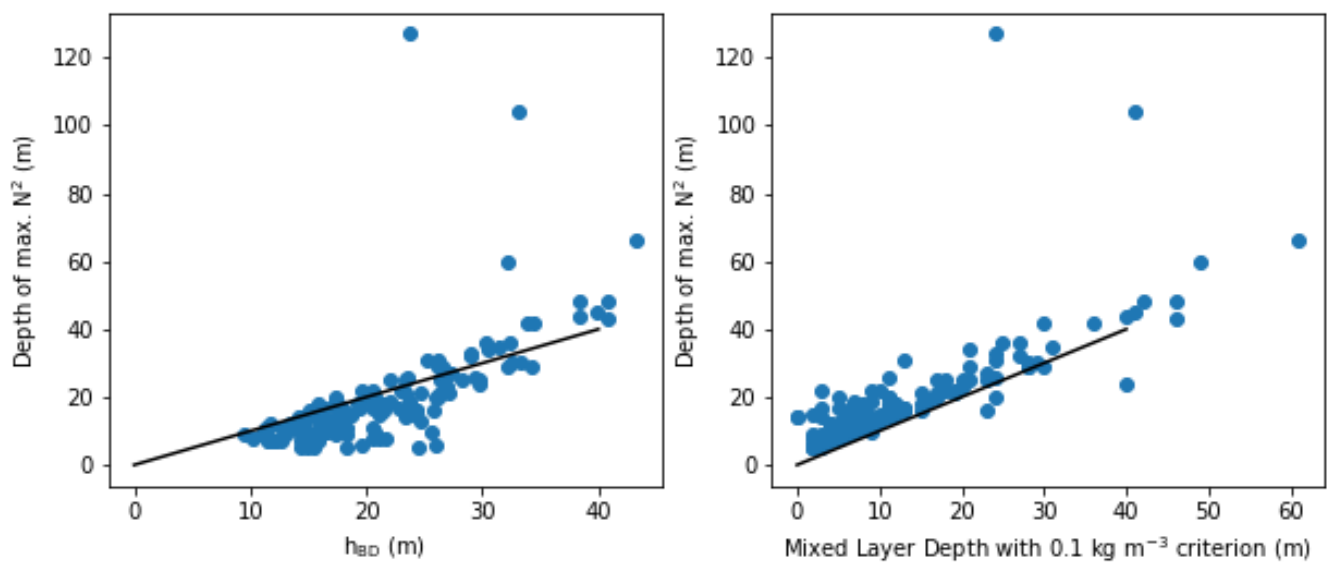

Figure 2.16: The depth of maximum $\mathrm{N}^{2}$ compared to (left) the equivalent mixed layer depth $\mathrm{h}_{\mathrm{BD}}$, and (right) a classical mixed layer depth defined by a $0.1 \mathrm{~kg} \mathrm{~m}^{-3}$ threshold. Solid black line: 1:1 relation. 


\section{Sea Ice and Open Water Days}

The "open water days" (OWD) parameter is defined as follows. First, we fix a time interval that captures the full sea ice variability in the region of interest, say from a date $T_{0}$ (here, taken to be doy 120, April 29) before the melt starts, to a later date $T_{e}$ when the ice extent has disappeared from the study area (here, doy 210, July 28). We then define the number of "open water days since sea ice retreat" (ODS) at a given location at time $T_{0}<t<T_{e}$ by simply summing the days where $c<15 \%$ since $T_{0}$, and the number of "Ice days until sea ice retreat" (IDU) by summing the days where $c>15 \%$ until $T_{e}$. Then OWD $\equiv$ ODS-IDU. Because the ice edge retreats steadily (does not meander much or go back and forth), there are very few sampling stations where IDU and ODS are both non-zero (Fig. S3.1). This was one of the reasons to conduct the experiment there in the first place and facilitates the analysis of the ice edge bloom. An instance where IDU and ODS are both non-zero will occur whenever a location has open water one day, but later on becomes ice covered again before the end of the melt season.

The steady retreat of the ice edge is demonstrated mainly by two facts: 1) ODS (Open water Days Since ice retreat) vs. IDU (Ice cover Days Until ice retreat) did not have much overlap where both are non-zero, and 2) there is a good correlation between distance from the ice edge and OWD (Open Water Days, defined as OWD $\equiv$ ODS-IDU)

The plot immediately below also demonstrates that as a consequence, an alternative definition of OWD, namely OWD=IDS when ice concentration is smaller than $15 \%$, and OWD $=-$ IDU when ice concentration is larger than $15 \%$, leads to largely identical values.
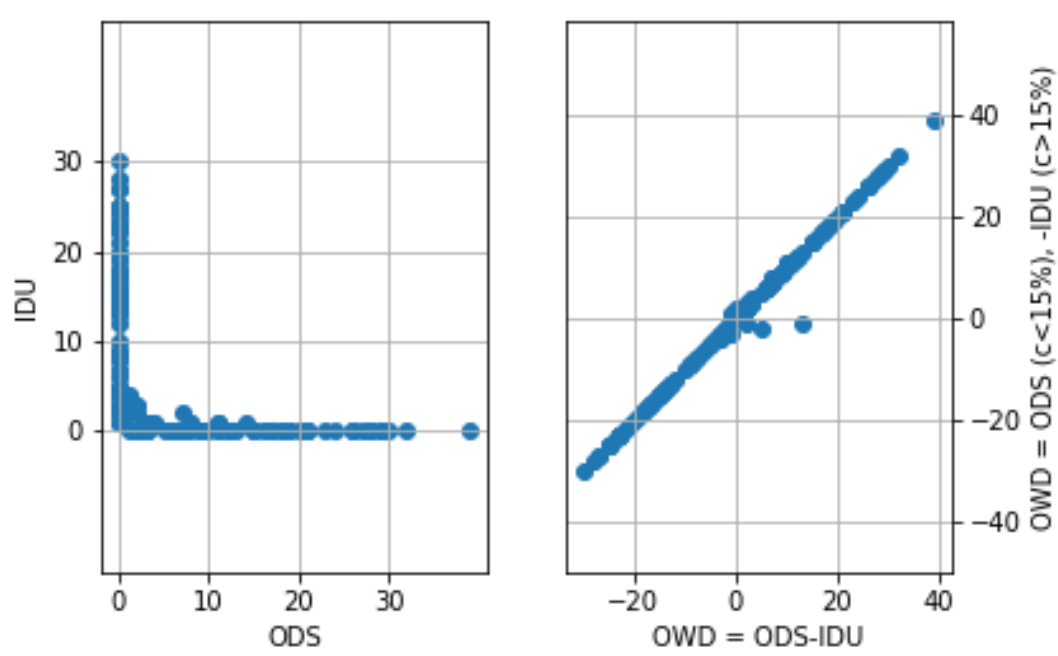

Figure 3.1: Left: Days until the ice retreats vs. days since the ice has retreated. Right: Comparison of two different criteria to define the OWD variable. 


\section{Light}

\subsection{Underwater light measurements using the C-OPS}

The C-OPS is an oceanographic instrument composed of a surface reference downwelling irradiance sensor, $E_{d}^{0+}(\lambda)$, as well as a set of two free-fall profiling radiometers (maximum depth of $125 \mathrm{~m}$ ), namely a downwelling irradiance one, $\mathrm{E}_{\mathrm{d}}(z, \lambda)$, and either a upwelling irradiance one, $\mathrm{E}_{\mathrm{u}}(z, \lambda)$, or an upwelling radiance one, $\mathrm{L}_{\mathrm{u}}(z, \lambda, \phi)$. Here, $\mathrm{z}$ denotes the depth, $\lambda$ the wavelength and $\phi$ the viewing angle (nadir in our case). These sensors record their respective radiometric quantity along nineteen wavelengths, spread in the visible spectrum, from $320 \mathrm{~nm}$ to $875 \mathrm{~nm}$. An ice floe version of this instrument, the so-called IcePRO, has been designed for deployment through an auger hole in an ice floe. (Once the IcePRO has been deployed in the hole, fresh snow is shoveled back in the hole before the profiling starts. This prevents any artificial bright spot just above the sensors.) Both versions have been used during the Green Edge project. The sensors have been factory calibrated before the cruise (January 2015 and February 2016), and a custom R code following the well recognized methodology originally published by Smith and Baker (1984) has been used to process the data. Furthermore, a PAR was computed from all the available multispectral irradiances values (in and above surface, downwelling and upwelling), following

$$
\operatorname{PAR}_{d}(\mathrm{z})=\int_{\lambda=400 \mathrm{~nm}}^{\lambda=700 \mathrm{~nm}} E_{\mathrm{d}}(\mathrm{z}, \lambda) \frac{\lambda}{\mathrm{hc}} d \lambda
$$

Here, $\mathrm{h}$ is Planck's constant and $\mathrm{c}$ is the speed of light in vacuum, and the summing is performed using a trapezoidal method.

When the data acquisition was performed in open water, the in-water radiometric quantities were extrapolated until $\mathrm{z}=0^{-}$, i.e. up to just under the surface, and when the data acquisition was performed under the ice, no extrapolation was performed, and the shallowest valid data point has been kept.

From the derived $\operatorname{PAR}_{d}(z)$ and $\operatorname{PAR}^{0+}$ quantities, a transmission profile was computed as

$$
\mathrm{t}(\mathrm{z})=\frac{\operatorname{PAR}_{\mathrm{d}}(\mathrm{z})}{\operatorname{PAR}^{0+}}
$$

This transmission profile includes the transmission loss due to the snow / sea ice layer, plus any water layer being between surface sensor and the profiling sensor when it is at the depth $\mathrm{z}$.

For no C-OPS station was it the case that it was both 1) sampled on ice and 2) AMSR2 indicated ice concentrations below $80 \%$, indicating a good match between in-situ sampling conditions and ice concentrations inferred by AMSR2. 


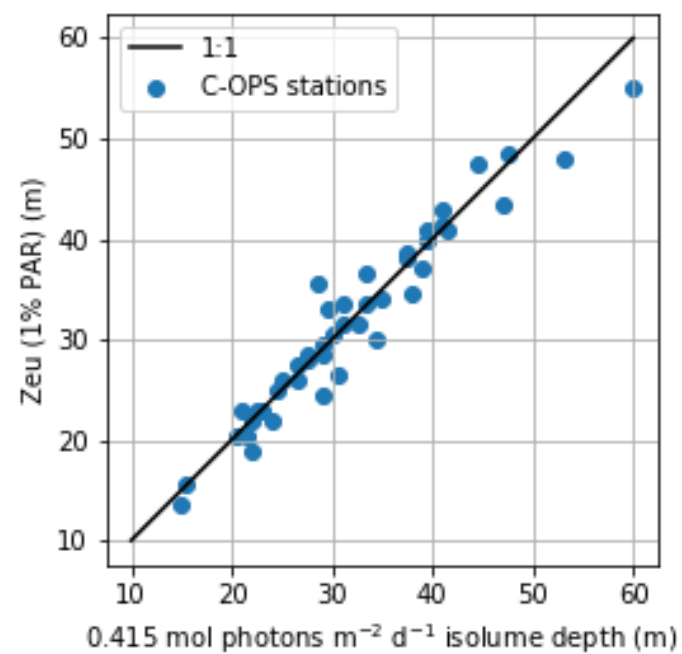

Figure 4.1: The $0.415 \mathrm{~mol}$ photons $\mathrm{m}^{-2} \mathrm{~d}^{-1}$ isolume plotted against the $1 \%$ PAR level, a common definition of the euphotic zone depth. The slope as determined by a linear regression is not significantly different from one.

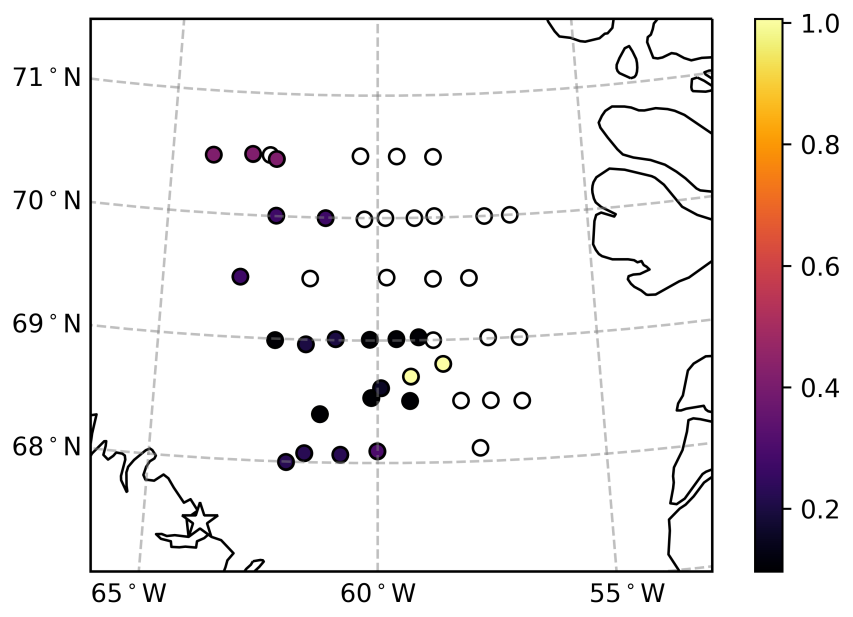

Figure 4.2: The combined ice+snow transmittance where available; empty circles mean that measurements were not done from the ice. Estimated from C-OPS measurements as the ratio between downwelling PAR irradiance directly under sea ice and the simultaneously measured incoming above-surface PAR. 

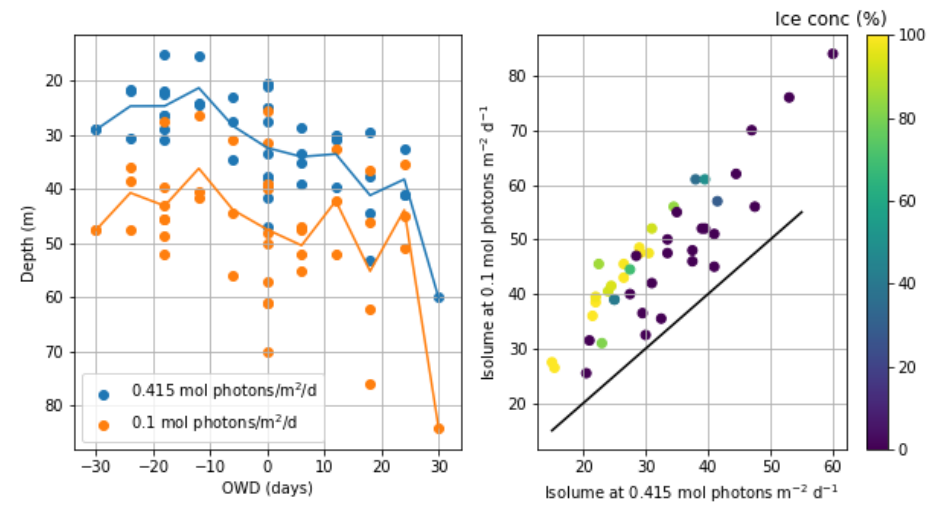

Figure 4.3: Isolumes compared between the 0.1 and the $0.415 \mathrm{~mol}$ photons $\mathrm{m}^{-2} \mathrm{~d}^{-1}$ light levels.

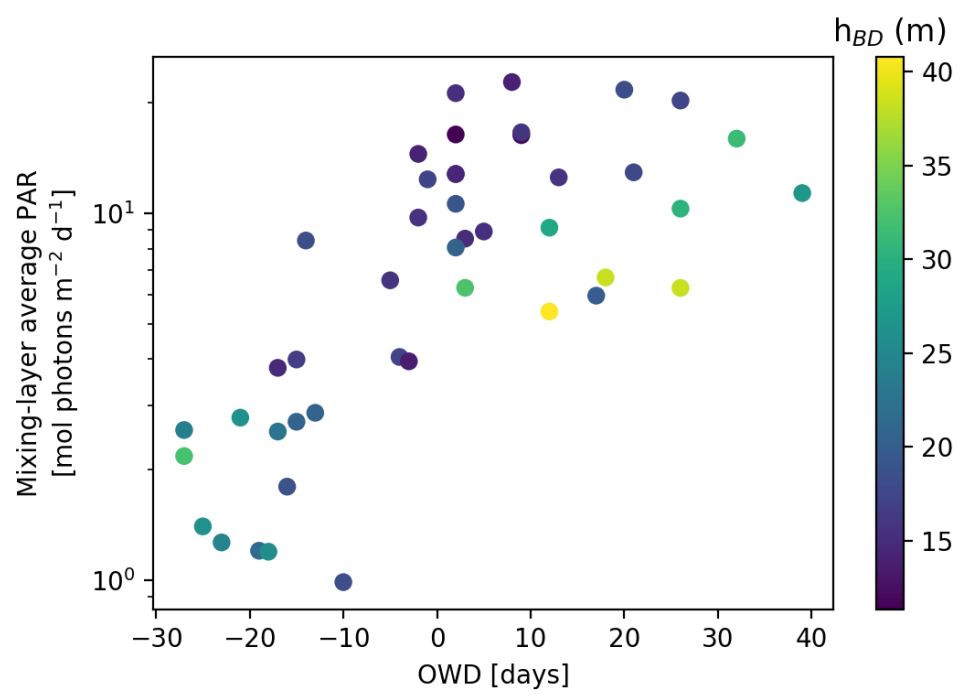

Figure 4.4: PAR irradiance averaged over the equivalent mixed layer depth $h_{B D}$. 


\subsection{Above-surface PAR irradiance}
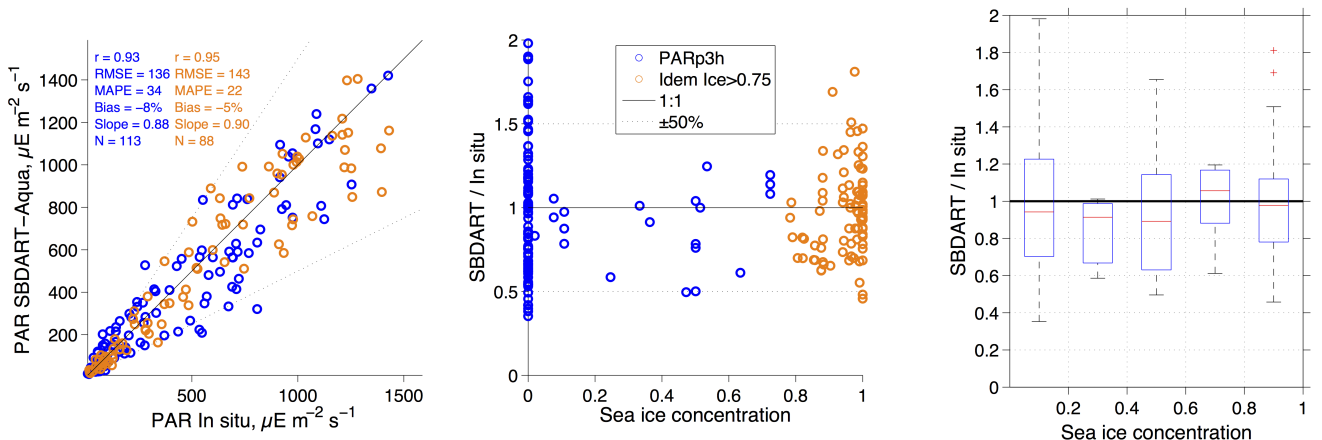

Figure 4.5: Scatterplot for the Amundsen cruise and a period of 3h prior to sampling (left), model/measurement ratio sorted by sea ice concentration (center), and boxplot of the model/measurement ratio sorted by five sea ice concentration categories (right) 


\section{5 “Arctic" vs. "Atlantic" domains}

The fuzzy c-means clustering algorithm (Ross, 2010) (implemented in python's skfuzzy library(scikitimage team)) assigns a membership value $\in[0,1]$ to each data point. All data points, characterized by a number of properties, are sorted into a pre-defined number of clusters (here, two).

Consequently, based on a few select properties, each hydrographic station is assigned a value between 0 and 1 , where 0 and 1 themselves correspond to exclusive membership in either cluster, and values in between represent the statistical uncertainty in the attribution (fuzziness).

The following properties were included, centered and normalized: (1) maximum temperature in the AW layer, (2) salinity at the estimated convection depth, and (3) ANP at 20 m depth, which summarize the strength of Atlantic inflow and the resulting hydrography and nutrient composition. The clustering reproduced as expected the longitudinal gradient present in the majority of all variables.
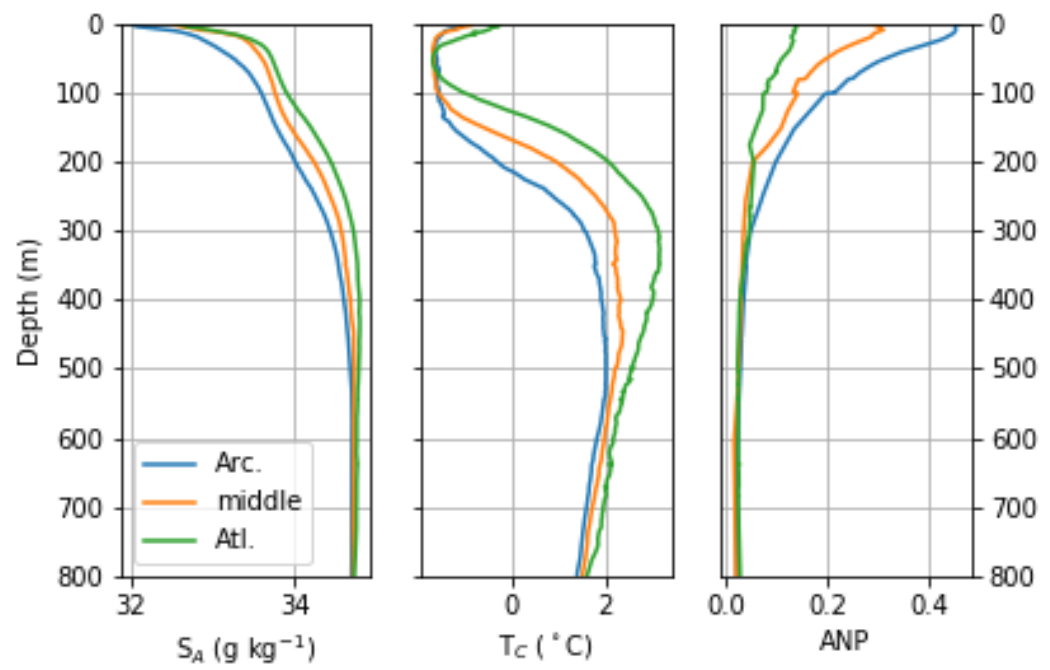

Figure 5.1: Salinity, temperature, and ANP tracer averaged in bins $0<0.1<0.9<1$ of the clustering coefficient. 


\section{Winter overturning depth and the associated pre-bloom nutrient inventory}
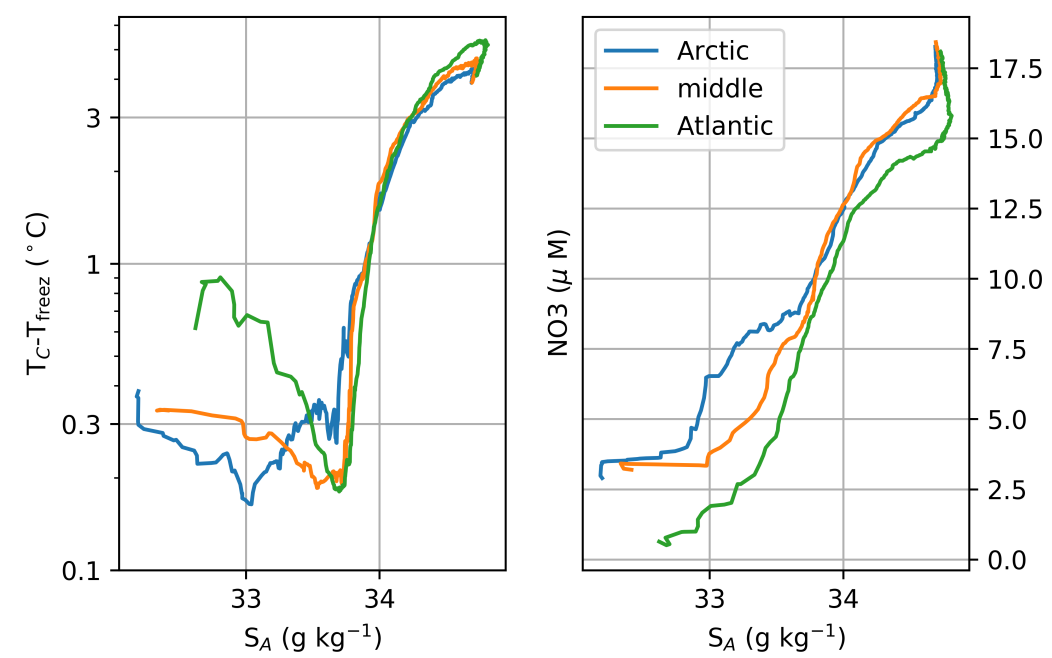

Figure 6.1: Left: Freezing point deviation plotted against salinity, split by hydrographic domain. For individual profiles, see Figs. S6.2 and S6.3. Right: Nitrate concentrations against salinity split by hydrographic domain. Although somewhat skewed because surface nitrate consumption had progressed more in the Atlantic than the Arctic domain, it shows how winter overturning to more saline layers gives access to more pre-bloom nitrate.

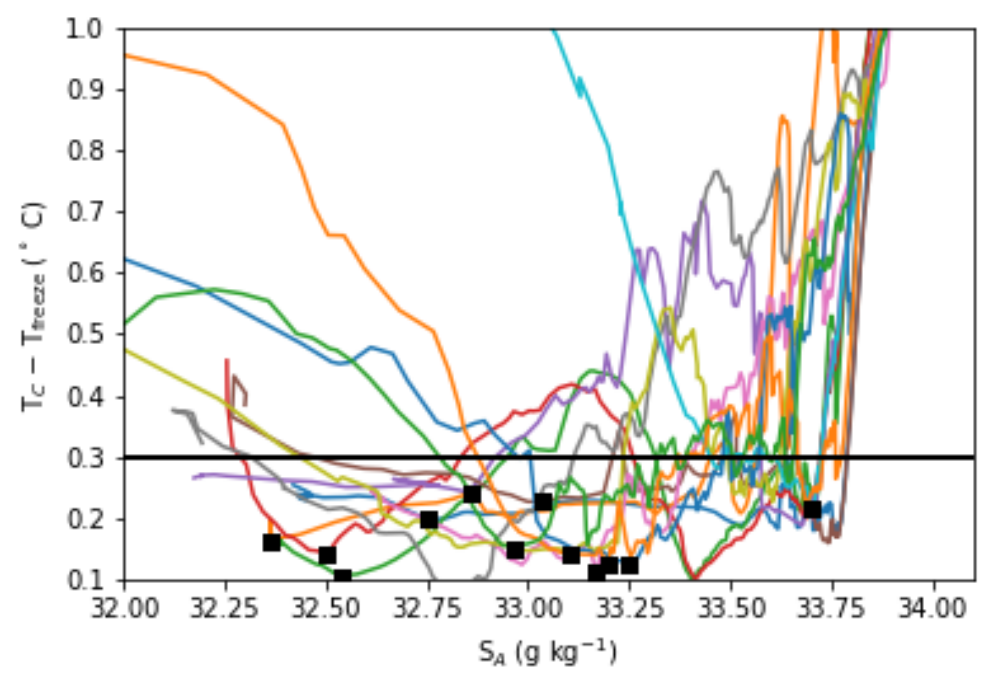

Figure 6.2: Temperature-salinity diagram showing detected temperature minima (black) in the "Arctic" domain. 


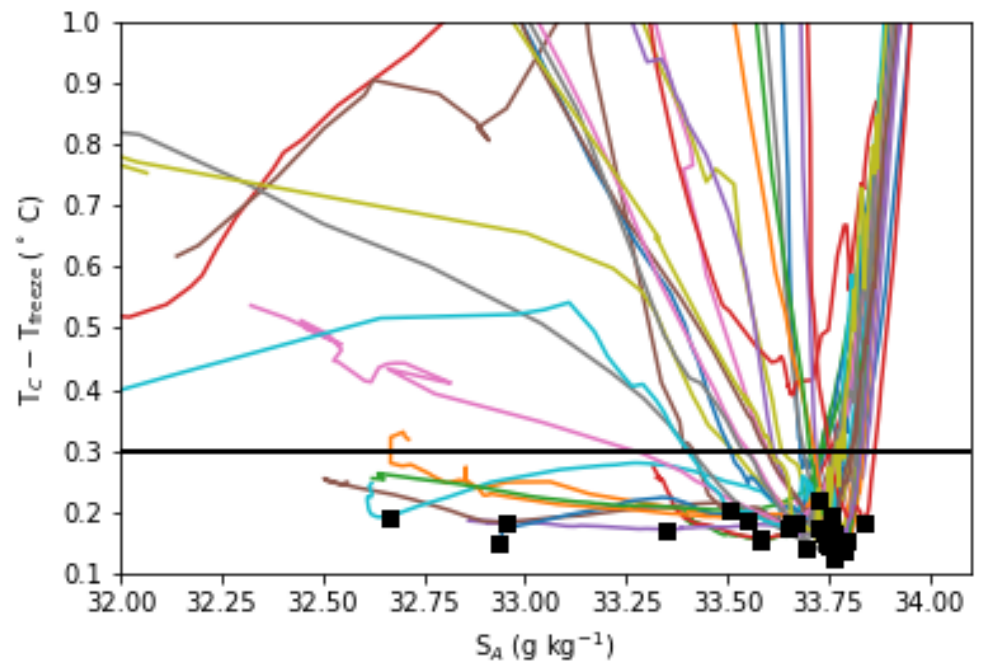

Figure 6.3: Temperature-salinity diagram showing detected minima (black) in the "Atlantic" domain.

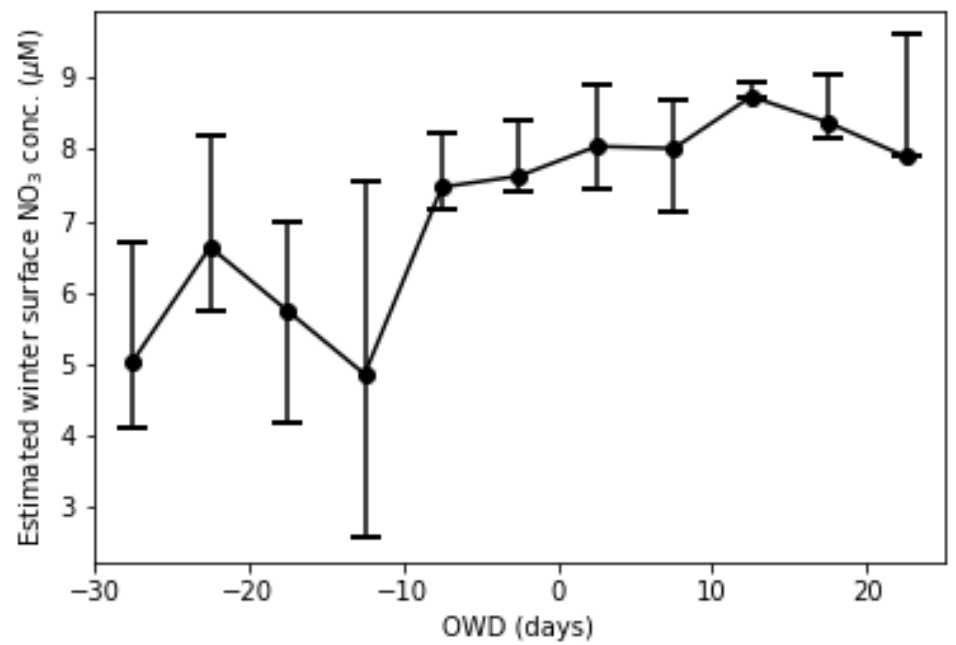

Figure 6.4: Winter surface concentration of nitrate taken as nitrate concentration at the estimated winter overturning salinity, plotted against the number of open water days. Note that in the easternmost stations (high OWD values), phytoplankton growth may have decreased nitrate concentrations at the winter overturning depth, and there winter surface concentrations may be more in the $10 \mu \mathrm{M}$ range. 


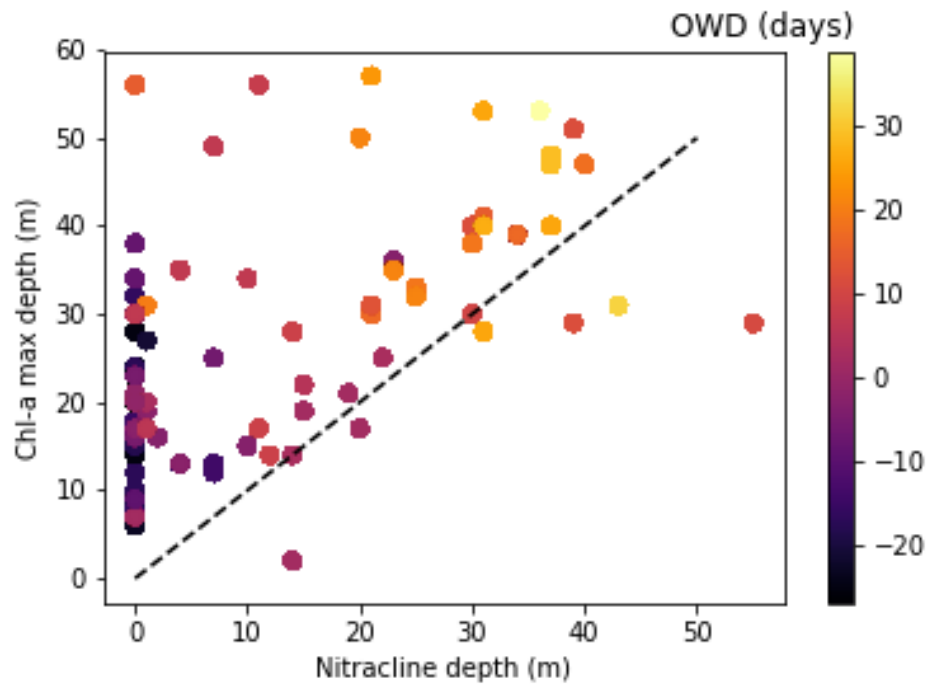

Figure 6.5: The chl-a maximum stayed below the nitracline at most stations. 


\section{Pacific and Atlantic water masses as separated by the phosphorus-nitrogen signature}

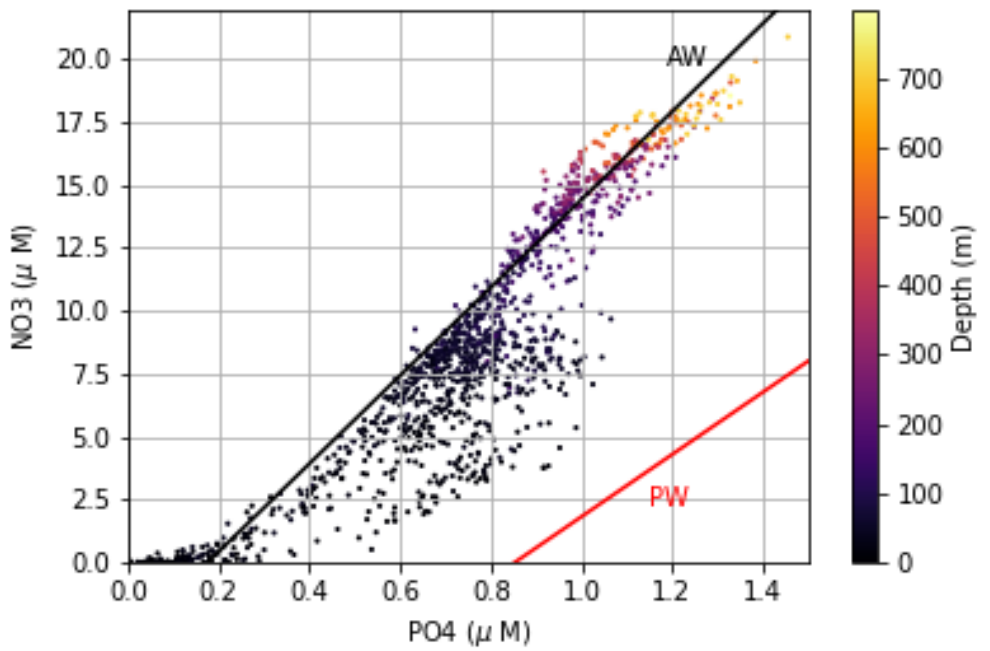

Figure 7.1: Nitrate vs phosphate, also showing regression relations by Jones et al. (1998). 


\section{Chlorophyll-a}

Integrating only over the full HPLC profile will underestimate integrated chl-a whenever the last HPLC value did not cover the entire fluorescence profile. In other words, integrating the calibrated chl-a fluorescence profile until the depth where fluorescence reaches $1 \%$ of its maximum value will yield a somewhat larger value.

The following two figures demonstrate that uniformly integrating HPLC-determined total chlorophyll-a to a depth of $80 \mathrm{~m}$ misses little overall biomass.

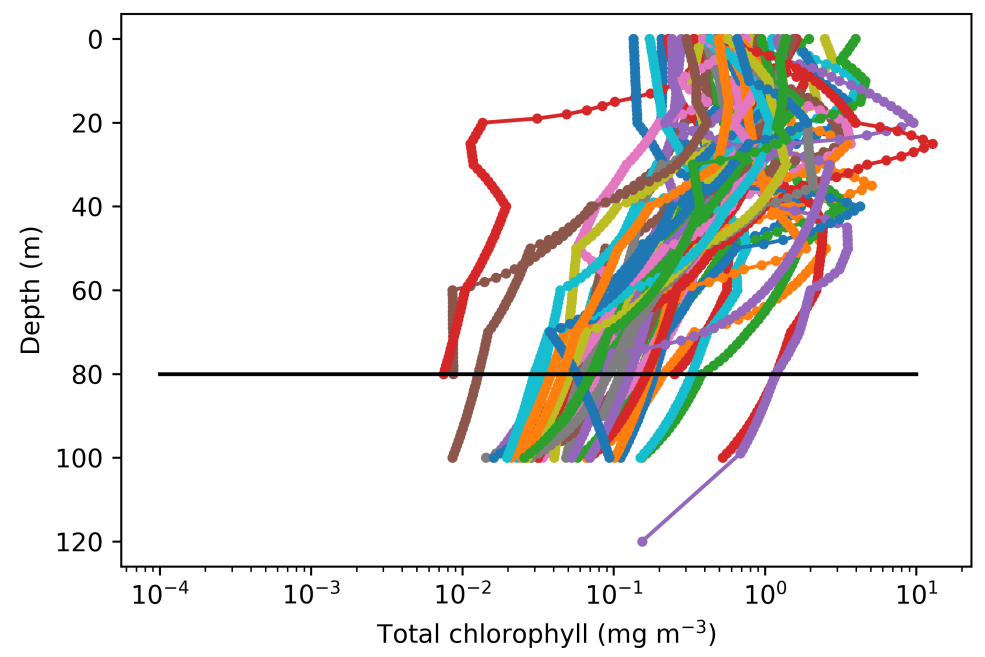

Figure 8.1: Vertical profiles of total chlorophyll-a as measured by HPLC, showing that very little biomass is lost by uniformly integrating from 0 to $80 \mathrm{~m}$ depth. 

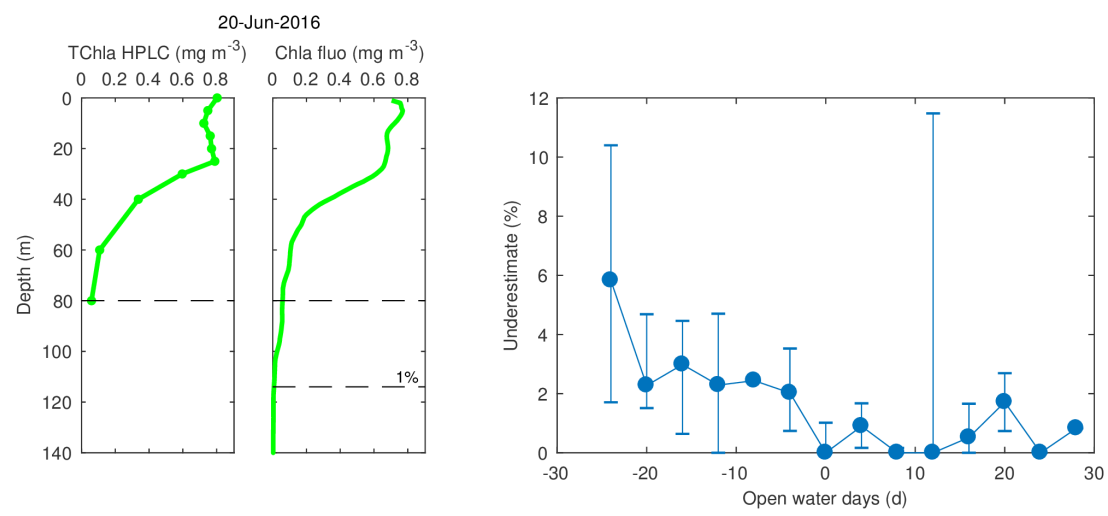

Figure 8.2: Underestimation of total chlorophyll by integration of HPLC-determined profiles to $80 \mathrm{~m}$, vs. closing them using CTD/rosette-based fluorescence sensor. Left panel: Two exemplary profiles of HPLC-determined total chlorophyll, and the corresponding CTD fluorescence sonde output (bias removed and smoothed using a 5-point running median filter followed by a 7-point running mean filter). The horizontal dashed black line marks the depth of the deepest TChla measurement while the dashed grey line marks the depth where only $1 \%$ of the maximum value of the Chla profile remains. Right panel: The underestimation of vertically integrated total chl-a by only integrating the HPLC profile, compared to integrating the complete fluorescence profile, as a function of open water days (OWD). The differences are small, which is why we used the simple vertical integration of HPLC total chl-a in this study. The underestimation is then given by the difference between the rosette chl-a fluorescence integrated down to the maximum HPLC sampling depth, and the rosette chl-a fluorescence integrated down to the $1 \%$ fluorescence level. 


\section{References}

Jones EP, Anderson LG, Swift JH. 1998. Distribution of Atlantic and Pacific Waters in the Upper Arctic Ocean: Implications for Circulations. Geophysical Research Letters 25(6): 765-768. ISSN 0094-8276. doi:10.1029/98g100464.

Peralta-Ferriz C, Woodgate RA. 2015. Seasonal and Interannual Variability of Pan-Arctic Surface Mixed Layer Properties from 1979 to 2012 from Hydrographic Data, and the Dominance of Stratification for Multiyear Mixed Layer Depth Shoaling. Progress in Oceanography 134: 19-53. ISSN 0079-6611. doi:http:/ /dx.doi.org/10.1016/j.pocean.2014.12.005.

Ross TJ. 2010. Fuzzy Logic with Engineering Applications. 3rd ed ed. Chichester, U.K: John Wiley. ISBN 978-0-470-74376-8. OCLC: ocn430736639.

scikit-image team. n.d. Skfuzzy 0.2 Documentation. https://pythonhosted.org/scikit-fuzzy/.

Smith RC, Baker KS. 1984. The Analysis Of Ocean Optical Data. pp. 119. doi:10.1117/12.943295. 